\title{
A EFETIVAÇÃO DO DIREITO À ASSISTÊNCIA SOCIAL ATRAVÉS DAS POLÍTICAS PÚBLICAS
}

\author{
Sheila Marques Nascimento Habib* \\ Dirlene Mendes Guimaraes*
}

\section{RESUMO}

O presente trabalho bibliográfico e documental, com utilização do método dedutivo-normativo, tem como objetivo contribuir para a análise da necessidade de criação de políticas públicas, assegurando o direito fundamental à assistência social, buscando a proteção da igualdade e a dignidade da pessoa humana. Demonstrando ainda a necessidade de uma ação governamental positiva através das políticas públicas para a sua efetivação de forma eficiente e duradoura, bem como verificar a existência corriqueira da justificativa no princípio da reserva do possível como forma de camuflar um ineficiente cumprimento do dever constitucional.

Palavras-chave: Direitos fundamentais sociais; assistência social; igualdade; políticas públicas; dignidade da pessoa humana.

\section{THE REALIZATION OF THE RIGHT TO SOCIAL ASSISTANCE THROUGH PUBLIC POLICIES}

\begin{abstract}
ABASTRACT
The present bibliographic and documentary work, using the deductive-normative method, aims to contribute to the analysis of the need to create public policies, assuring the fundamental right to social assistance, seeking the protection of equality and the dignity of the human person. It

\footnotetext{
* Mestranda em Direito Constitucional pela Universidade Metodista de Piracicaba, Advogada, Endereço eletrônico: sheila_marques_2000@ hotmail.com, Endereço postal: Rua Aquilino Pacheco, 1370, 131, Bairro Alto, CEP 13.419-50, Piracicaba/SP.

* Mestranda em Direito Constitucional pela Universidade Metodista de Piracicaba, Especialista em Direito do Trabalho e Direito Previdenciário pela UNIVEM - Marília/SP, Advogada, Endereço eletrônico: dirlene.mendes@hotmail.com, Endereço postal: Rua Dr. Alvin, 338, Bairro São Dimas, CEP 13.416-259, Piracicaba/SP. 
also demonstrates the need for positive governmental action through public policies for its effective and lasting implementation, as well as to verify the existence of justification in the principle of reserving the possible as a way to disguise an inefficient fulfillment of constitutional duty.

Keywords: Basic social rights; social assistance; equality; public policy; dignity of human person

\section{INTRODUÇÃO}

O presente artigo busca inicialmente expor o conteúdo histórico do surgimento dos direitos fundamentais sociais no ordenamento jurídico, iniciado na Constituição Mexicana de 1917 e, após, pela Constituição de Weimar em 1919.

A propósito, no Brasil, os direitos fundamentais sociais tiveram suas primeiras previsões na Constituição de 1934, utilizando-se a Constituição de Weimar como inspiração. Ressaltase, por oportuno, que a assistência social apesar de já ter sido abordado em outras constituições brasileiras, somente na Constituição Federal de 1988 esse direito foi efetivamente previsto como fundamental sendo regulamentado de forma especifica e definido como um direito sujeito a ações prestacionais do poder público.

Dentro dos direitos sociais fundamentais previstos no artigo $6^{\circ}$ da Constituição Federal Vigente (direitos de segunda geração) têm-se o direito à previdência social onde a assistência social é considerada uma ramificação deste direito a qual será principal objeto do presente trabalho.

Contudo, por tratar-se de um direito que será efetivado por meio de ações positivas do poder público, resta imprescindível a implementação de políticas públicas para tal fim.

Neste contexto, fundamental a reflexão sobre o papel do poder público em implementar políticas públicas com fins de resguardar direitos sociais, em especial ao direito à assistência social considerada com uma norma de aplicabilidade limitada.

Para que as políticas públicas sejam implementadas no Brasil é necessário a elaboração de um plano de criação bem definido, sendo levantado o fim específico, objetivos, principais diretrizes, instrumentos e sistema, ou seja, é necessário um planejamento pré-estabelecido.

No Brasil, a assistência social tem suas diretrizes previstas nos artigos 6º 194, 203 e 204 da Constituição Federal de 1988, contudo, esses dispositivos apesar de regulamentarem o 
direito à assistência social, não possuem os detalhamentos necessários para a sua aplicação de forma imediata, carecendo de uma ação positiva do estado para sua efetivação. É justamente com este intuito que foi criado em 1993 a Lei $\mathrm{n}^{\circ}$ 8.742, conhecida como Lei Orgânica da Assistência Social - LOAS, sendo uma política pública implementada pelo governo para regulamentar o direito à assistência social, com vistas a garantir o atendimento às necessidades básicas dos segmentos populacionais vulnerabilidades pela pobreza e pela exclusão social, dentre outras medidas.

Desta forma, as políticas públicas possuem um relevante papel na aplicação e efetivação dos direitos fundamentais sociais, em especial ao direito à assistência social, vez que possibilitam uma eficiente execução do acesso ao direito, contribuindo para o avanço na manutenção da dignidade da pessoa humana. Segundo Veroneze (2017, p. 354) "nestes últimos anos, assim como as demais políticas públicas, a Assistência Social também tem sofrido com os ataques neoliberais e neoconservadores de políticos descomprometidos com a realidade da população brasileira, valorizando os setores econômicos em detrimento do social".

O Brasil ainda possui uma insatisfatória implementação de políticas públicas eficientes, seja por desinteresse estatal de pratica-las ou por limitação orçamentária, se dando por satisfeitos em respeitar apenas a reserva do possível, que é tratado no ordenamento brasileiro como um princípio que limita a atuação e abrangência do Estado frente as necessidades sociais, sendo este um argumento utilizado pelo poder público de forma recorrente com objetivo, na maioria das vezes, em justificar uma ineficiência de gestão da administração pública. Desta forma, infelizmente, ainda o que se vê na prática são instituições privadas por meio de instituições filantrópicas, por exemplo, cumprindo o papel que seria do poder público na implementação de medidas para aplicação do direito social.

Diante da análise bibliográfica proposta, utilizando-se do método dedutivo normativo, o presente trabalho busca demonstrar a necessidade que o direito fundamental à assistência social possui de implementação de políticas públicas eficientes, vez que tratam de normas de eficácia limitada, carecendo de prestações positivas do governo. Ainda demonstrará que nem sempre essas políticas públicas são implementadas da forma que deveriam ser, sendo essa ineficiência justificada na reserva do possível e, portanto, desrespeitando a igualdade e a dignidade da pessoa humana.

Sem a pretensão de atingir todas as particularidades que o tema exige, acreditamos que será de grande relevância abordar, mesmo que de forma sintética, a importância que as políticas públicas possuem para direitos sociais prestacionais, mais precisamente, o direito à assistência 
social, sendo necessário uma alerta para o poder público na valoração desse instituto que necessita muito além do que prevê o reserva do possível e o mínimo existencial.

\section{Breve análise do surgimento dos direitos fundamentais sociais.}

Com o surgimento do constitucionalismo no século XVIII, os direitos fundamentais (individuais e coletivos) representam a principal garantia dos cidadãos de que o Estado se conduzirá pela liberdade e pelo respeito da pessoa humana (LUNCORVITE, 2010)

Os direitos fundamentais são direitos e garantias, sejam eles individuais, sociais, políticos ou jurídicos que objetivam a regulamentação de proteções inerentes ao ser humano, sejam natos ou naturalizados. Neste sentido, afirma de Oliveira Junior (2010, p. 109) que os direitos fundamentais "englobam a normatividade protetiva dos vários aspectos que circunscrevem o ser humano e sua dignidade".

Os direitos fundamentais sociais surgiram em meados do século XIX, a partir de quando a sociedade começou a ser despertada em relação a esses direitos observando um considerável aumento do tratamento desumano e ao mesmo tempo uma inércia do Estado em relação a esta situação. Nas palavras de Mastroid (2008, p.75) “os direitos individuais clássicos, declarados como fundamentais pelas Revoluções Liberais, se apresentaram como limites contra a intervenção do Estado e de terceiros".

Após o surgimento dos direitos sociais, suas primeiras previsões legais tratavam de proteções estritamente individuais, ou seja, a cada pessoa de forma particular, porém, com o passar do tempo viu-se a necessidade de ampliar o público alvo desses direitos de forma que atingissem maior número de pessoas (direito difuso).

Segundo Kim (2015), essa mudança ocorreu com:

A passagem do individualismo exacerbado para o reconhecimento da existência de direitos de alguns sociais, em especial, após as manifestações que resultaram na elaboração de constituições republicanas, ficou mais evidente com a Declaração Universal dos Direitos do Homem de 1948, que tratou de quatro ordens de direitos individuais: direitos pessoais do indivíduo, direitos do indivíduo em face das coletividades, liberdades públicas e direitos públicos, e os direitos econômicos e sociais, estes decorrentes do amadurecimento de novos valores e de exigências ligadas ao bem-estar por meio do Estado. (KIM, 2015, p. 169)

Os direitos sociais nasceram através do surgimento de descontentamentos das classes operárias em relação aos excessos do capitalismo, sendo que, nesta época já notava-se a insuficiência dos direitos liberais. Diante deste quadro de insatisfação geral quanto à liberdade, foi promulgada a Constituição do México, em 1917, conhecida como "Constituição Política 
dos Estados Unidos Mexicanos”, que trouxe uma primeira visão geral do que seria os direitos sociais. Na dicção de Silva (2008, p.285) "a ordem social como ordem econômica, adquiriu dimensão jurídica a partir do momento em que as constituições passaram a discipliná-la sistematicamente, o que teve início com a Constituição Mexicana de 1917”.

Em 1919, a Constituição Alemã, conhecida como “Constituição de Weimar” inseriu em seu texto legal os primeiros direitos sociais, que após alguns anos viria a ser utilizada como inspiração para outros países do mundo. Neste sentido, afirma Comparato (2010, p.66-67) "a plena afirmação dos direitos fundamentais sociais somente veio ocorrer no século XX, com a Constituição Mexicana de 1917 e a Constituição de Weimar de 1919, cuja positivação serviu de influência para as constituições de diversos países".

Ainda em 1919, outro grande marco na busca de promover a justiça social, foi a criação da OIT- Organização Internacional do Trabalho, neste sentido afirma Alvarenga (2008) que:

A Organização Internacional do Trabalho foi criada pela Conferência da Paz,
assinada em Versalhes, em junho de 1919, logo após a Primeira Guerra
Mundial, e teve como objetivos promover a justiça social e, em particular,
respeitar os direitos humanos no mundo do trabalho. Desde a sua criação,
portanto, a OIT está assente no princípio, inscrito na sua Constituição, de que
não pode haver paz universal duradoura sem justiça social. (ALVARENGA,
2008, p.1)

Posteriormente a criação dessas constituições, várias outras começaram a inserir em seus textos, direitos fundamentais sociais, como foi o caso da Constituição do Brasil em 1934 que foi redigida conforme seu preâmbulo para "organizar um regime democrático que assegure a Nação, a unidade, a liberdade, a justiça e o bem-estar social econômico" (BRASIL, 1934), sendo considerada a primeira Constituição do Brasil a mencionar sobre a ordem econômica e social tendo como inspiração a Constituição de Weimar.

Neste sentido, assevera Moraes (2018),

Direitos sociais são direitos fundamentais do homem, caracterizando-se como verdadeiras liberdades positivas, de observância obrigatórias em um Estado Social de Direitos, tendo por finalidade a melhoria de condições de vida aos hipossuficientes, visando à concretização da igualdade social, e são consagrados como fundamentos do Estado democrático, pelo art. $1^{\circ}$, IV, da Constituição Federal. (MORAES, 2018, p.302).

Ainda, afirma Silva (2008),

[...]os direitos sociais, como dimensão dos direitos fundamentais do homem, são prestações positivas proporcionadas pelo Estado direta ou indiretamente, enunciadas em normas constitucionais, que possibilitam melhores condições de vida aos mais fracos, direitos que tendem a realizar a igualização de 
situações sociais desiguais. São, portanto, direitos que se ligam aos direitos de igualdade. (SILVA, 2008, p. 286-287)

Os direitos fundamentais em sua maioria estão previstos na Constituição Federal Vigente, de forma expressa, contudo, existem direitos fundamentais presentes em todo o ordenamento jurídico e neste sentido, dispõe Coelho (2017):

Em resumo, impede reconhecer que as disposições inseridas na Constituição da República não esgotam todos os direitos fundamentais passíveis de reconhecimento pelo Estado brasileiro, eis que estes direitos podem se exteriorizar de forma expressa (mais comum), implícita ou decorrente de regime constitucional e de tratados internacionais subscritos pelo Brasil. (COELHO, 2017, p.56)

Esses direitos sociais são considerados desdobramentos do direito de igualdade, classificados como direitos de segunda geração que exigem uma ação positiva do poder público. Neste sentido, para Kim (2015):

É fato que os direitos fundamentais de segunda dimensão acabaram por passar por um "ciclo de baixa normatividade", como já salientado por autores como Paulo Bonavides, ou tiveram eficácia duvidosa, eis que, diante de sua própria natureza de direitos a prestações materiais, nem sempre foram considerados resgatáveis pela sua baixa concretude, pela carência de recursos ou, ainda, pela limitação essencial de vontade política. (KIM, 2015, p. 168)

Desta forma, os direitos de segunda geração foram criados pelo legislador para ter uma eficácia plena e aplicabilidade direta, cumprindo integralmente sua "missão" constitucional (igualdade e dignidade entre os seres humanos). Ainda na visão do doutrinador Silva (2008, p.290), esses direitos "valem como pressupostos do gozo dos direitos individuais na medida em que criam condições materiais mais propicias aos aferimentos de igualdade real, o que, por sua vez, proporciona condição mais compatível com o exercício efetivo da liberdade".

Certamente, se não for possível ocorrer essa aplicabilidade direta dos direitos sociais, necessário se faz que o poder público de forma positiva, crie medidas alternativas para uma concreta efetivação desses direitos, como por exemplo, a implementação de políticas públicas. Por fim, assevera Reis e Cerqueira (2011, p. 332) que, "não basta que os direitos sociais sejam reconhecidos e declarados, é necessário que sejam garantidos. E a experiência constitucional brasileira comprova que a reiterada afirmação desses direitos nos textos constitucionais não tem sido garantia necessária e suficiente de sua efetivação".

\section{A assistência social como um direito fundamental social e sua normatização no Brasil.}


A partir da criação dos direitos fundamentais, estes sofreram classificações em dimensões, sendo que segundo Bonavides (2011):

Os direitos fundamentais passaram na ordem institucional a manifestar-se em três gerações sucessivas, que traduzem sem dúvida um processo cumulativo e quantitativo, o qual, segundo tudo faz prever, tem por bússula uma nova universalidade: a universalidade material e concreta, em substituição da universalidade abstrata e, de certo modo, metafísica daqueles direitos, contida no jusnaturalismo do século XVIII. (BONAVIDES, 2011, p. 563)

Necessário frisar que a separação dos direitos fundamentais em "gerações" não implica na interpretação de que uma superou a outra, mais sim que foram surgindo em momentos distintos, sendo criados de forma progressiva na medida em que uns foram complementando os outros e ao mesmo tempo sendo base para criação de novos direitos.

Os direitos fundamentais sociais surgiram após a Revolução Industrial, no século XVIII, momento em que a classe burguesa passou a ser maioria dominante, e assim, iniciando grandes movimentos para o crescimento de produções e riquezas. Neste sentido, afirma Branco (2017):

Após a Revolução Industrial, tendo a burguesia alcançado a posição de classe social dominante, esta não via limites para seu anseio de ampliação da produção e das riquezas, impondo condições indignas à classe trabalhadora recém-constituída, fazendo, então, com que se estabelecesse a luta do proletariado pela instituição de direitos diretamente ligados ao valor igualdade, com vistas à implementação de prestações materiais e jurídicas que pudessem reduzir as desigualdades no plano fático (BRANCO, 2017, p. 81)

Em consequência a essa busca desenfreada de riquezas, a classe trabalhadora passou a ser tratada de forma indigna e exploradora, despertando o início de uma luta contra a burguesia para que fossem reconhecidos os direitos de igualdade, foi neste momento que surgiram as primeiras acepções a respeito dos direitos fundamentais sociais.

Neste sentido, segundo Branco (2011):

O descaso para com os problemas sociais que veio a caracterizar o État Gerdame, associado às pressões decorrentes da industrialização em marcha, o impacto do crescimento demográfico e o agravamento das disparidades no interior da sociedade, tudo isso gerou novas reinvindicações, impondo ao Estado um papel ativo na realização da justiça social. O ideal absenteísta do Estado liberal não respondia, satisfatoriamente, às exigências do momento. Uma nova compreensão do relacionamento Estado/sociedade levou os Poderes Públicos a assumir o dever de operar para que a sociedade lograsse superar as suas angústias estruturais. Daí o progresso estabelecimento pelos Estados se seguros sociais variados, importando intervenção intensa na vida econômica e a orientação das ações estatais por objetivos de justiça social. (MENDES E BRANCO, 2011, p.155) 
O Brasil antes da criação da Constituição de 1934 tratava do instituto da assistência social como um instrumento de caridade, altruísta, humanitário, não havendo qualquer tipo de previsão legal que desse a esse instituto a proteção como um direito em si. Nessa época, as ações vinculadas à assistencial social eram advindas de movimentos não governamentais, sendo que o poder público não tinha interferência direta, ficando apenas como um "figurante", subsidiando quando necessário fosse, porém sem nenhuma vinculação legal.

Durante muito tempo, a Igreja Católica assumiu o papel de prestar a assistência social à população como forma de caridade, sendo que somente após os anos de 1930 iniciaram movimentos advindos do poder público em transformar a assistência social em um direito normativo constitucionalmente protegido.

Após a promulgação da Constituição de 1934, surgiram as primeiras previsões de direitos fundamentais sociais em seu texto legal, e consequentemente as primeiras leis infraconstitucionais que tratavam diretamente do direito à assistência social, como, por exemplo, a Lei n 91, de 1935 (BRASIL, 1935), criada pelo então Presidente Getúlio Vargas. Esta lei determinava "regras pelas quais são a sociedade declaradas de utilidade pública", havendo previsão da assistência social e, inclusive, menções sobre repasses orçamentários para esse fim.

Em 1938, foi criado por Getúlio Vargas o CNSS - Conselho Nacional do Serviço Social com objetivo de opinar sobre questões sociais e subvenções a obras sociais, este órgão permaneceu por longos anos em vigência, sendo extinto pelo atual CNAS previsto na Lei de LOAS (BRASIL, 1993).

Contudo, essa proteção social só veio a ser consolidada de fato, no período do pósguerra, neste sentido afirma Coelho (2017), senão vejamos:

Todavia, é com o pós-guerra (1945) que esse sistema de proteção social consolida o modelo de Estado social francês, também conhecido como Estado-Providência ou Estado de Bem-Estar Social. Este, por sua vez, "caracteriza-se por ser um modelo de proteção social baseado na ideia de redistribuição de recursos pelo Estado (solidariedade nacional) e financiado, majoritariamente, por um sistema de seguridade social por repartição. (COELHO, 2017, p. 82)

A propósito, apesar do tema assistência social ter sido abordado em alguns momentos das constituições passadas, foi na Constituição Federal de 1988 que esse direito se achou efetivamente previsto como fundamental, sendo criados particularidades da sua aplicação e efetivação. Nesse sentido, afirma Veroneze (2017, p. 347) que “ a passagem da assistência social enquanto uma prática arcaica, tradicional, conservadora, para uma prática inovadora, 
inserida no campo do direito e concebida como política pública aconteceu somente com o advento da Constituição Federal de 1988”.

$\mathrm{Na}$ atual Constituição Federal do Brasil, os direitos fundamentais sociais foram concretizados de forma definitiva como direitos que garantem a manutenção da igualdade pautada na dignidade da pessoa humana, sendo direitos efetivados através de ações positivas do poder público. Neste sentido, afirma Coelho (2017):

Esses direitos, denominados de segunda geração, vinculam-se, sobretudo nos dias atuais, à imperiosa necessidade de respeito ao que se convencionou chamar de "mínimo existencial" ou "mínimo de existência condigna" do indivíduo e, embora estejam condicionados à disponibilidade orçamentária de um Estado, as normas que os informam devem se dotadas de força normativa que lhes garantam efetiva concretização. (COELHO, 2017, p. 31)

A Constituição Federal de 1988, em seus artigos $6^{\circ}$ ao 11 dispõe da previsão de direitos sociais, sendo classificados por Silva (2008) como

"[...] (a) direitos sociais relativos ao trabalhador; (b) direitos sociais relativos à seguridade, compreendendo os direitos à saúde, à previdência $\mathrm{e}$ assistência social (c) direitos sociais relativos à educação e à cultura; (d) direitos sociais relativos à moradia; (e) direitos sociais relativos à família, criança, adolescente e idoso; (f) direitos sociais relativos ao meio ambiente. (SILVA, 2008, p.287) [grifo nosso]

Por oportuno, ressalta-se que, dentre os direitos sociais previstos no artigo $6^{\circ}$ da Constituição, anteriormente citada, será objeto deste estudo os direitos fundamentais sociais com ênfase no direito à assistência social.

$\mathrm{O}$ direito à assistência social também se encontra previsto em outros dispositivos da Carta Magna, como nos artigos 203 e 204 que preveem os objetivos e diretrizes que devem ser seguidos na criação de políticas públicas para sua efetivação.

Desta forma, este direito diz respeito há um lado mais universal da seguridade social, pois será prestada a quem dela necessitar independente de contribuição, ao contrário do que ocorre com a previdência social, que possui caráter contributivo. Neste sentido, afirma Veroneze (2017, p. 353) “A proteção social não-contributiva distingue-se da previdência social e do seguro social, que são proteções contributivas pré-pagas e só se destinam aos filiados à Previdência Social e não a toda população".

Essa inexistência de contraprestação "financeira" pelo beneficiário está amparada pelo artigo 204 da Constituição Federal (BRASIL, 1998) que prevê um orçamento próprio destinado à assistência social, senão vejamos: “As ações governamentais na área da assistência social serão realizadas com recursos do orçamento da seguridade social, previstos no art. 195, além de outras fontes $[\ldots]$ ".." 
Ressalta-se por oportuno, que a prévia contribuição pelo contribuinte não seria possível, vez que, os destinatários desse direito em um primeiro momento não podem ser identificados, necessitando se enquadrar em algum dos objetivos trazidos no artigo 203 da Constituição Federal (BRASIL, 1988) para usufruírem da assistência social.

O Poder Público é considerado "protetor" na aplicação e efetivação dos direitos fundamentais, sejam eles individuais ou sociais, portanto, a assistencial social prevista expressamente no caput do artigo $6^{\circ}$ tem como fundamento a proteção das pessoas consideradas hipossuficientes, ou seja, aqueles que não possuem condições de proverem a sua própria subsistência, carecendo de ações do poder público para garantir uma vida com o mínimo de dignidade. Desta forma, afirma Veroneze (2017) que:

Estes parâmetros mostram que a garantia dos direitos foi um processo que envolveu o esforço da população e dos movimentos sociais na efetivação dos direitos absorvidos para uma política que contemplasse a Declaração do Direitos Humanos, colocando a dignidade da pessoa humana no centro das discussões. (VERONEZE, 2017, p. 349)

A respeito da definição do objetivo da assistência social conclui Veroneze (2017) que:

Os direitos sociais são aqueles que têm por objetivo garantir aos indivíduos sociais condições materiais tidas como imprescindíveis para o pleno gozo dos seus direitos, por isso tendem a exigir do Estado uma intervenção na ordem social que assegure os critérios se equidade e justiça distributiva. Assim, diferentemente dos direitos à liberdade, se realizam por meio de atuação estatal com a finalidade de diminuir as desigualdades sociais. (VERONEZE, 2017, p.349)

É justamente por se tratar de um direito direcionado ao hipossuficiente, ou seja, pessoas consideradas incapazes de manter sua subsistência, ou de tê-la promovida por sua família (BRASIL, 1988), que o excluí de ser um direito fundamental social universal, como ocorre com outros direitos sociais (educação, saúde, por exemplo), sendo necessário a definição previa pelo legislador de seus requisitos, com fim de delimitar o termo "desamparados". Esses requisitos estão descritos nos incisos I ao V do artigo 203 da $\mathrm{CF}$, considerados como delimitador dos destinatários da assistência social.

No Brasil, existem vários serviços públicos sem custos, prestados àqueles que necessitarem ser amparados pelo direito à assistência social, como por exemplo, o benefício de prestação continuada (BPC) previstos na Loas - Lei Orgânica da Assistência Social que prevê a garantia de um salário mínimo mensal à pessoa com deficiência e ao idoso, conforme art. 20 da Lei 8.742 (BRASIL, 1993). "O benefício de prestação continuada é a garantia de um saláriomínimo mensal à pessoa com deficiência e ao idoso com 65 (sessenta e cinco) anos ou mais 
que comprovem não possuir meios de prover a própria manutenção nem de tê-la provida por sua família."

Em 1993, o Presidente da República Itamar Franco, sancionou a Lei 8.742/93 (BRASIL, 1993), mais conhecida como LOAS - Lei Orgânica da Assistência Social, considerada como uma política pública criada pelo governo para garantir aos indivíduos uma aplicação eficiente do direito à assistência social previsto na Constituição Federal de 1988.

Importante ressaltar ainda uma outra política pública implementada pelo governo brasileiro com fim de cumprir o disposto no artigo 25 da Lei 8.742/93 (BRASIL, 1993) que dispõe a respeito "dos projetos em enfrentamento da pobreza", com intuito de promover a erradicação da extrema pobreza, incrementado o programa do bolsa família, buscando garantir o direito à alimentação, o acesso à educação e à saúde.

A referida Lei Orgânica da Assistência Social - LOAS é mencionada, por muitos doutrinadores, como o principal instrumento legislativo de viabilização do direito à assistência social no Brasil, sendo um grande progresso para a busca da igualdade.

Por fim, frisa-se que a questão mais polêmica do direito à assistência social nos dias atuais é a dependência que a mesma possui de ações prestacionais pelo poder público, vez que se trata de um direito previsto expressamente na Constituição Federal de 1988, porém, por ser norma de eficácia limitada, depende de formas exteriores de concretização, como as políticas públicas, sendo este um grande problema enfrentado atualmente em decorrência de, dentre outros fatores, uma má gestão por porte do poder público como veremos nos próximos tópicos.

\section{As políticas públicas e seus benefícios na efetivação do direito fundamental social à assistencial social.}

Os direitos sociais possuem como objetivo uma maior promoção da justiça distributiva e à concretização da igualdade social, contudo, nem sempre esses objetivos são aplicados na prática. Isso ocorre por inúmeros fatores, porém, tem-se a questão orçamentária como considerado o mais recorrente dentre eles. Neste sentido, segundo Reis e Cerqueira (2011, p. 333) "no que tange aos obstáculos operacionais, tem-se que os direitos sociais, em razão de sua natureza prestacional, necessitam, para sua implementação, de recursos públicos que são escassos". 
Contudo, mesmo que ainda haja grandes dificuldades na materialização desses direitos, existem medidas adotadas pelo poder público, como as políticas públicas, que possibilitam essa materialização de forma eficiente como afirma Schafer (2013):

(...) os direitos sociais só podem ser efetivamente exercitados quando o poder público coloca à disposição do usuário um serviço e quando vem a cumprir com obrigações constitucionais e infraconstitucionais instituídos por uma política pública social, tudo em virtude de um de seus elementos caracterizadores, qual seja, a "função promocional do Estado. (SCHAFER, 2013, p.55)

As políticas públicas foram criadas com as Revoluções Liberais, período em que se iniciou o Estado de Direito Democrático e Constitucionalizado, em que houve uma globalização econômica, sendo, segundo Garcia $(2009$, p. 127) consideradas como "concretas formas de agir em razão dos interesses da comunidade, de modo a alcançar a justiça social, a segurança e o desenvolvimento econômico e social ambientalmente sustentável"

Segundo Moretti e Costa (2016), ainda têm que:

Em síntese, as políticas públicas constituem em programas de atuação do Poder Executivo os quais buscam definir as áreas sociais que devem ser priorizadas, planejar os objetivos a serem alcançados, analisar os instrumentos disponíveis para sua realização, bem como direcionar os recursos públicos necessários para a consecução desses objetivos. (MORETTI e COSTA, 2016, p. 120),

A intenção do legislador quando da criação dos direitos fundamentais sociais na Constituição de 1988, não foi a de gerar essa "dependência" em fatores externos para sua efetivação, porém, o que se vê na prática é a necessidade de uma ação estatal prestacional para a efetivação de quase todos os direitos sociais, sendo que alguns destes, como a assistência social, não possui uma outra forma de efetivação da norma constitucional, que não seja através de implementações de políticas públicas, conforme aborda Cliveira (2013, p.158), senão vejamos:

[...] é importante salientar que, no âmbito do direito fundamental à assistência social, há a prevalência de normas constitucionais que não são diretamente aplicáveis: basta analisar os artigos da Constituição que tratam do tema. Por consequência, em regra insuscetível estão de gerar direitos públicos subjetivos imediatos, ante a ausência de densidade normativa suficiente a exigir a prestação estatal viabilizadora da norma de direito fundamental. Por tal motivo, o legislador deve, por meio da incrementação de políticas públicas, conferir densidade normativa suficiente ao direito à assistência social como modo de garantir a sua máxima efetividade. (CASTRO E OLIVEIRA, 2013, p.158) 
Importante ressaltar que, para que uma política pública seja implementada no país é necessário que seja levado em consideração vários fatores para que de fato atinja o seu principal objetivo. Neste sentido, segundo Coelho (2017):

[...] não basta ao administrador público, dentro das possíveis maneiras de implementar uma determinada política, optar por aquela que seu juízo subjetivo, de modo aleatório, entender mais adequada. Há de se fazer a opção por aquela que melhor consiga representar o comportamento ótimo, o que, em última análise, vincula-se à ideia de optar por aquela que mais consiga concretizar direitos. (COELHO, 2017, p. 137)

Isto posto, nota-se que as políticas públicas possuem um relevante papel na aplicação e efetivação dos direitos fundamentais sociais, vez que possibilitam uma eficiente execução do acesso ao direito, contribuindo para o avanço na manutenção da igualdade e dignidade da pessoa humana.

O direito à assistência social como já mencionado, busca reparar as necessidades do hipossuficiente econômico, e, para sua efetivação necessário se faz uma intervenção prestacional do poder público. Assim preleciona Veroneze (2017):

\begin{abstract}
A assistência social não só provê os bens materiais, mas também articula com os outros setores da sociedade civil e com as outras políticas sociais para que os indivíduos sociais e as famílias sejam tratados com dignidade e façam valer os seus direitos. A assistência social configura-se, assim, como possibilidade de reconhecimento público da legitimidade das demandas sociais de seus usuários e dos espaços de ampliação de seu protagonismo. A proteção social oferecida pelo Estado deve garantir a segurança de sobrevivência (de rendimento e de autonomia), de acolhida e de convívio ou vivência familiar e direito à vida. (VERONEZE, 2017, p. 349)
\end{abstract}

Contudo, na prática, o Brasil ainda possui uma insatisfatória implementação de políticas públicas eficientes, seja por desinteresse estatal de pratica-las ou por limitação orçamentária, na maioria das vezes respeitando apenas a reserva do possível, sendo este um argumento utilizado pelo poder público de forma recorrente com objetivo de justificar uma "má gestão" da administração pública.

Para Coelho (2017),

A adoção absoluta da "reserva do possível" para afastar a responsabilidade do Estado na concretização dos direitos sociais poderia levar ao esvaziamento do conteúdo jurídico dos direitos sociais e ao esfacelamento do Estado Social de Direito, tal como assegurado pela Constituição da República do Brasil, trazendo, assim, imensas dificuldades ao exercício pleno da cidadania. (COELHO, 2017, p.142)

Como veremos a seguir, o argumento do cumprimento da reserva do possível, não raras vezes é utilizado como forma de justificar o não cumprimento de suas responsabilidades com 
os direitos sociais, não havendo por parte do governo movimentos a fim de buscar uma gestão administrativa e orçamentária responsável para a criação e manutenção de políticas públicas, não só no que diz respeito à assistência social, mas também em relação aos demais direitos fundamentais, sejam individuais ou sociais.

\section{O princípio da reserva do possível, dignidade da pessoa humana e o mínimo existencial}

O princípio da reserva do possível teve origem em 1972, pelo Tribunal Federal da Alemanha, no caso conhecido como "Numerus Clausus".

No Brasil, a reserva do possível é adotada para os casos que envolvem falta de recursos do Poder Público frente aos direitos que exigem prestações continuadas, ou seja, foi dada uma interpretação diversa para o instituto da reserva do possível. Em outras palavras, ela pode ser definida como um "apoio" ao governo para definir um limite orçamentário destinados à concretização de direitos fundamentais, mais especificadamente aqueles que exigem uma prestação do poder público, como ocorre com os direitos sociais, em especial, a assistência social. Neste sentido, para Sarlet e Figueiredo (2008) têm-se:

De acordo com a noção de reserva do possível, a efetividade dos direitos sociais a prestações materiais estaria sob a reserva das capacidades financeiras do Estado, uma vez que seriam direitos fundamentais dependentes de prestações financiadas pelos cofres públicos. (SARLET; FIGUEIREDO, 2008, p. 10)

Ainda nesta mesma perspectiva, segundo Nunes Jr. (2009, p.171), a reserva do possível é "a concretização dos direitos fundamentais sociais ficaria condicionada ao montante de recursos previstos nos orçamentos das respectivas entidades públicas para tal finalidade".

A questão é que, não raras vezes, o poder público se utiliza do fundamento respaldado na reserva do possível para justificar uma ineficiente prestação dos direitos sociais ao indivíduo, direito este resguardado pela Carta Suprema.

Ademais, a afirmação de Reis e Cerqueira (2011, p. 338) sobre o assunto se mostra de grande valia, senão vejamos: “Assim, aceitar a alegação de inexistência de orçamento suficiente como justificativa para a não implementação dos direitos fundamentais sociais significa afirmar que o custo impede a concretização do texto constitucional”.

Neste sentido, ainda afirma Moraes (2010)

No que toca à disponibilidade de recursos financeiros estatais, destaca-se a doutrina da "reserva do possível", segundo a qual a efetivação dos direitos sociais estaria limitada às possibilidades orçamentárias do Estado. Muitos criticam a aplicação sem restrições dessa teoria, defendendo a possibilidade 
de intervenção nas escolhas orçamentárias e imposição ao Poder Público de determinadas prestações, em especial aquelas relacionadas ao "mínimo existencial". (MORAES, 2010, p.1)

Desta forma, é inegável a dependência dos direitos fundamentais sociais à disponibilidade dos recursos públicos econômicos, porém, a questão vai além disso, pois os destinatários desses direitos sociais ficam à mercê não só da disponibilidade orçamentária, mais principalmente da ineficiência da governabilidade, má gestão, o que na realidade, gera na maioria dos casos uma crise econômica do poder público, e, consequentemente, cortes orçamentários destinados a políticas públicas.

Como já analisado, a reserva do possível possibilita ao Estado se ater há limites financeiros disponíveis para execução de medidas a serem implementadas para efetivação dos direitos fundamentais tanto individuais quanto sociais, porém devendo sempre ser observado o mínimo existencial.

Conforme afirma Mastrodi (2008),

De fato, a reserva do possível pode ser considerada como um argumento válido quando apresentada em termos absolutos (ausência total de recursos), o que justifica a falta da promoção de políticas públicas em países pobres, como algumas nações africanas e asiáticas.

No entanto, tal reserva não é justificativa para negar ações sociais em países com economias consideradas entre as maiores do mundo, como é o caso do Brasil. Numa situação como a brasileira, a reserva do possível nada é senão pretexto para justificar a negativa de intervenção estatal em prioridades sociais. (MASTRODI, 2008, p.103-104)

A Constituição Federal do Brasil é conhecida como uma constituição "humana" sendo necessário a proteção e observância da dignidade da pessoa humana para que a Constituição seja legítima (SARLET, 2011, p.92).

Ainda, segundo Sarlet (2011):

[...] apesar da possibilidade de se questionar a vinculação direta de todos os direitos sociais (e fundamentais em geral) consagrados, na Constituição de 1988 com o princípio da dignidade da pessoa humana, não há como desconsiderar ou mesmo negar tal conexão, tanto mais intensa, quanto maior a importância dos direitos sociais para a efetiva fruição de uma vida com dignidade [...]. (SARLET, 2011, p.114)

Abordando a necessidade da observância do princípio da dignidade humana no ordenamento jurídico, seja ele nacional ou internacional, assegura Josué Mastrodi (2008) que:

$\mathrm{O}$ valor da dignidade da pessoa, resgatado do direito natural, passou aos poucos a ser considerado princípio tanto de direito internacional quanto de direito interno nos mais diversos países, inclusive no Brasil, que o positivou como princípio constitutivo do Estado. Dessarte, nenhuma norma, nenhum ato 
jurídico deve ser editado ou praticado em afronta a esse valor, erigido à condição de princípio constitucional. (MASTRODI, 2008, p.32)

A dignidade da pessoa humana é um princípio fundamental que possui características as quais fornecem estrutura e apoio para a criação e aplicação não só dos direitos fundamentais, mais de todo ordenamento jurídico. Neste sentido, segundo Sarlet (2011):

(...) também os assim denominados direitos sociais, econômicos e culturais, seja na condição de direitos de defesa (negativos), seja na sua dimensão prestacional (atuando como direitos positivos), constituem exigência e concretização da dignidade da pessoa humana. (SARLET, 2011, p. 108)

Importante considerar o princípio da universalidade dos direitos fundamentais ${ }^{61}$, apesar de não estar consagrado expressamente na Carta Magna de 1988 assegura que ao menos os direitos e garantias fundamentais ali expressos devem ser reconhecidos e aplicados a todos (independentemente de nacionalidade) em respeito à dignidade da pessoa humana, contudo, deve sempre ser reconhecido as exceções dos direitos cuja titularidade exigem uma circunstância específica, como por exemplo ocorre nos direitos políticos (SARLET, 2011, p.117).

O direito à assistência social (direito fundamental social) é reconhecido como um direito de cunho prestacional, ou seja, exige do Estado uma prestação para que seja efetivado.

A importância da efetivação dos direitos sociais se ampara na questão do direito à igualdade, sendo está uma forma de "reparar" as diferenças existentes entre os seres humanos na sociedade, e, portanto, garantia da existência digna da pessoa humana. (SARLET, 2011, p.110)

É papel do Governo assegurar e garantir esse "mínimo existencial” ao cidadão, seja por meio de leis, política públicas, bem como outras ações indiretas que atinjam esse fim, resguardando sempre os direitos fundamentais básicos. (ISMAEL FILHO, 2016)

\footnotetext{
${ }^{1}$ Tem-se por Universalidade: tendo em vista que os direitos e garantias fundamentais vinculam-se ao princípio da liberdade, conduzido pela dignidade da pessoa humana, os mesmos devem possuir como sujeito ativo, todos os indivíduos, independente da raça, credo, nacionalidade, convicção política, a coletividade jurídica em geral, podendo pleiteá-los em qualquer foro nacional ou internacional, conforme devidamente expresso no parágrafo 5 na Declaração e Programa de Ação de Viena de 1993. DIOGENES JUNIOR, Jose Eliaci Nogueira. Aspectos gerais das características dos direitos fundamentais. Âmbito Jurídico, v.100, p. XV, 2012. Disponível em: 〈http://www.ambitojuridico.com.br/site/?n_link=revista_artigos_leitura\&artigo_id=11749>. Acesso em: $04 \mathrm{de}$ set. 2018.
} 
A dignidade da pessoa humana está diretamente ligada ao mínimo existencial, vez que para que se tenha uma vida com dignidade, necessária se faz, ter acesso há uma qualidade de vida saudável. Neste sentido, para Queiroz (2006), tem-se como mínimo existencial o seguinte:

Proibição da insuficiência", cuja finalidade é auxiliar no acompanhamento da concretização dos direitos sociais, quando se define, a partir da Constituição, um conteúdo mínimo de direitos fundamentais, ao qual o legislador estaria vinculado e proibido de suprimir sem uma compensação adequada. (QUEIROZ, 2006, p. 105-110)

Garantir a qualquer ser humano a segurança básica, para Gosepath (2013).

[...] consistente em um mínimo existencial que lhe deve ser garantido, através da proteção da sua integridade física e psíquica em todas as suas dimensões, mediante a oferta de uma assistência social, permitindo que qualquer indivíduo possa viver a sua vida de forma digna, autodeterminada e livre". (GOSEPATH, 2013, p.79-80)

É incontestável que o ser humano necessita de um mínimo existencial para ter uma vida digna, cabendo ao Estado proporcionar meios indispensáveis para que esse mínimo existencial seja garantido e fornecido a todo ser humano. Desta forma, afirma Coelho (2017, p. 31) sobre os direitos sociais (de segunda geração) e o mínimo existencial que "embora esteja condicionado à disponibilidade orçamentária de um Estado, as normas que os informam devem ser dotadas de força normativa que lhes garantam efetiva concretação”.

Queiroz (2006, p.22) assevera que “essa `garantia de um mínimo social’ - ou `standard mínimo`compreendido como `mínimo existencial` - destina-se a evitar a perda total da função do direito fundamental de forma que este não resulte esvaziado de conteúdo`, ou seja, para que não reste "desprovido de sentido".

É indiscutível a importância que a efetiva aplicação dos direitos sociais tem na vida do indivíduo, principalmente do hipossuficiente, vez que estes necessitam da satisfação das necessidades básicas do ser humano pois só assim estará assegurada a sua dignidade humana.

Os direitos sociais previstos no artigo $6^{\circ}$ da Constituição Federal (BRASIL, 1988) como educação, saúde, alimentação, trabalho, moradia, transporte, lazer, segurança, previdência social, proteção à maternidade e a infância e assistência aos desamparados, são direitos que todos os cidadãos possui para que ter uma vida saudável, digna, e assim exercer sua liberdade no plano individual e social.

Neste diapasão, diante a importância de assegurar uma vida digna ao ser humano, fazse necessário atentar para a questão do papel do Estado em assegurar os direitos fundamentais, em especial, o direito à assistência social, vez que a visão deve ser feita de forma ampla e construtiva, ou seja, o objetivo do Estado não deve ser o fornecimento do mínimo para reparar 
essa insuficiência, mas ir além disso, os gestores públicos não devem se acomodar com o mínimo, não sendo este visto como "a linha de chegada", mais sim, transformando-o em "ponto de partida" sempre em busca de sedimentar a igualdade entre todos como bem assevera a Constituição Federal de 1988.

Neste sentido, afirma Clève (2006):

Logo, a perspectiva social dos direitos fundamentais possui um horizonte de realização progressiva, o qual aponta não para a ideia de mínimo de bem-estar social, mas de máximo. Porém, trata-se de um máximo possível, à luz das riquezas do país em questão e do comprometimento do governo/sociedade em realizá-lo (CLÈVE, 2006, p. 28-39).

Por fim, o mínimo existencial não possui uma limitação concreta para sua efetivação, abrindo portas para que ocorra sempre de forma progressiva e eficaz, devendo ser compreendido como a busca da máxima qualidade de vida, e é neste momento que as políticas públicas são vistas como formas de intermediar e garantir meios para que sejam efetivadas medidas que buscam viabilizar uma melhor qualidade de vida, principalmente com dignidade a todo ser humano, sendo imprescindível para isto, que o poder público deixe de se ater somente à reserva do possível e passe a buscar uma administração pública eficiente e responsável, pois dessa forma, certamente, o integral cumprimento do direitos à assistência social previsto na Carta Magna por meio da implementação de efetivas políticas públicas será alcançado.

\section{CONSIDERAÇÕES FINAIS}

Diante deste cenário, em que pesem o aumento da implementação de políticas públicas no Brasil, principalmente para garantia da efetivação dos direitos fundamentais sociais de segunda geração, ainda não são suficientes para uma efetiva aplicação dos direitos sociais como demanda o texto constitucional.

A própria realidade prática enfrentada pelo Brasil nos dias atuais, nos demonstra essa ineficiência do poder público na implementação de políticas públicas para efetivação de direitos fundamentais sociais, em especial, no que demonstra este escrito, a assistência social.

Essa ineficiência decorre tanto por desinteresse estatal em praticá-las, como a limitação orçamentária, pautando de forma recorrente no argumento do respeito à "reserva do possível" e, objetivando na maioria das vezes, em justificar uma gestão administrativa ineficiente.

Tratando-se em específico do direito à assistência social como um direito fundamental social previsto no artigo $6^{\circ}$ da Constituição Federal de 1988, considerado ramo da previdência 
social, refere-se a um direito que necessita de ser disponibilizado pelo poder público por meio de prestações, ações positivas, portanto, possuindo uma dependência significativa da criação de políticas públicas.

Avaliar os impactos da política de assistência social em relação à ineficiência de gestão do poder público em criar meios para sua efetivação é relevante, na medida em que necessário se faz buscar uma nova visão do que seria um "mínimo existencial" adequado, para só assim definir qual o limite "ideal” da reserva do possível o poder público deve se pautar.

Desta forma, se o poder público passar a utilizar-se da reserva do possível de forma eficiente e responsável, deixando de utilizá-la como mera justificativa para o cumprimento de uma "obrigação" constitucional, os resultados práticos da efetivação de direitos fundamentais sociais seriam muito mais proveitosos e relevantes.

Por fim, o que se parece mais profícuo na atual conjuntura, seria o poder público buscar gerir a administração pública de forma mais responsável, sustentável e eficiente, pois, desta forma, a efetivação do direito à assistência social, bem como de todos direitos fundamentais sociais previstos na Constituição Federal de 1988, obteriam um resultado mais efetivo, ou seja, além do mínimo existencial, garantindo uma vida com respeito, justiça e dignidade.

\section{REFERENCIAS}

ALVARENGA, Rúbia Zanotelli de. A Organização Internacional do Trabalho e a proteção aos Direitos Humanos do trabalhador. In: Âmbito Jurídico, Rio Grande, XI, n. 52, abr 2008. Disponívelem:http://ambitojuridico.com.br/site/?n_link=revista_artigos_leitura\&artigo_id=25 10\&revista_caderno=25>. Acesso em 09 mar. 2019.

BONAVIDES, Paulo. Curso de Direito Constitucional. 26a ed. São Paulo: Malheiros, 2011. BRASIL. Constituição (1934). Constituição da República dos Estados Unidos do Brasil. Rio de.Janeiro,1934.Disponível.em:http://www.planalto.gov.br/ccivil_03/constituicao/constituica o34.htm>. Acesso em 10 mar. 2019.

. Constituição (1988). Constituição da República Federativa do Brasil. Brasília, DF:

Senado Federal: Centro Gráfico, 1988. 292 p. Disponível em: < http://www.planalto.gov.br/ccivil_03/constituicao/constituicaocompilado.htm>. Acesso em 10 mar. 2019.

declaradas de 28 utilidade 2 pública. http://www.planalto.gov.br/ccivil_03/LEIS/1930-1949/L0091.htm>. Acesso em: 05 de mar. 2019.

Lei Federal n. 8.742, de 7 de dez. 1993. Disciplina sobre a organização da Assistência.Social.e.dá.outras.providências..Disponível.em:<http://www.planalto.gov.br/ccivi 1_03/leis/L8742compilado.htm>. Acesso em: 10 mar. 2019.

CASTRO, Artur Soares de; OLIVEIRA, João Carlos Cabrelon de. Direito fundamental à assistência social: Algumas considerações - Fundamental right to social assistance: some considerations. Revista da SJRJ, Rio de Janeiro, 20, p.151-172, abr.2013. Disponível em: 
<https://www.jfrj.jus.br/revista-sjrj/artigo/direito-fundamental-assistencia-social-algumasconsideracoes-fundamental-right> Acesso em: 09 mar. 2019.

CLÈVE, Clémerson Merlin. A eficácia dos direitos fundamentais sociais. Revista de Direito Constitucional e Internacional, São Paulo, 54, p.28-39, jan. /mar 2006.

COELHO, Rodrigo Batista. Direitos fundamentais sociais e políticas públicas: subjetivação, justiciabilidade e tutela coletiva do direito à educação. Leme: Habermann Editora, 2017.

DE OLIVEIRA JUNIOR, José Alcebíades. DIREITOS FUNDAMENTAIS SOCIAIS E DESAFIOS DE EFETIVAÇÃO. Revista Direitos Culturais, [S.1.], v. 5, n. 9, p. 109-118, Mai. 2011. ISSN 2177-1499. Disponível em: <http://srvapp2s.santoangelo.uri.br/seer/index.php/direitosculturais/article/view/486/238>. Acesso em: 12 mar. 2019.

DIOGENES JUNIOR, Jose Eliaci Nogueira. Aspectos gerais das características dos direitos fundamentais. Âmbito Jurídico, v.100, p. XV, 2012. Disponível em: <http://www.ambitojuridico.com.br/site/?n_link=revista_artigos_leitura\&artigo_id=11749>. Acesso em: 04 mar. 2019.

GARCIA, Maria da Glória F.D.P. Direito das políticas públicas. Coimbra: Almedina, 2009. GOSEPATH, Stefan. Uma pretensão de direito humano à proteção fundamental. Tradução de Cláudia Toledo e Bráulio Borges Barreiros. In: TOLEDO, Cláudia (Org.). Direitos Sociais em debate. Rio de Janeiro: Elsevier, 2013.

KIM, Richard Pae. Separação de poderes e as teorias interna e externa dos direitos fundamentais: direitos sociais e a inaplicabilidade da teoria externa. Cadernos Jurídicos, n.40, ano 16, p. 165-187, abril-junho. 2015. Disponível em: <https://bdjur.stj.jus.br/jspui/bitstream/2011/101629/separacao_poderes_teorias_kim.pdf> Acesso em: 10 mar. 2019.

QUEIROZ, Cristina. O princípio da não reversibilidade dos direitos fundamentais sociais: princípios dogmáticos e prática jurisprudencial. Coimbra: Coimbra Editora, 2006. MASTRODI, Josué. Direitos Sociais Fundamentais. Rio de Janeiro: Lumen Juris, 2008 MENDES, Gilmar Ferreira; BRANCO Paulo Gustavo Gonet. Curso de Direito Constitucional. 6 ${ }^{\text {a }}$ ed. São Paulo: Saraiva, 2011.

MORAES, Alexandre de. Direito constitucional. 34 ed. São Paulo: Atlas, 2018

MORAES, Daniela Pinto Holtz. Efetividade dos direitos sociais: Reserva do possível, mínimo existencial e ativismo judicial. In: Âmbito Jurídico, Rio Grande, XIII, n. 76, maio 2010. Disponívelem:http://www.ambitojuridico.com.br/site/index.php?n_link=revista_artigos_leitur a\&artigo_id=7701>. Acesso em 13 mar. 2019.

MORETTI, Deborah Aline Antonucci; COSTA, Yvete Flavio da. A importância do ativismo judicial na implementação dos direitos sociais não implementados pelo poder público. Revista de Direitos e Garantias Fundamentais. v.17, n. 1, jan/jun. 2016. Disponível em: <http://sisbib.emnuvens.com.br/direitosegarantias/article/view/750>. Acesso em 13 mar. 2019. SARLET, Ingo Wolfgang. Dignidade da pessoa humana e direitos fundamentais. Porto Alegre: Livraria do Advogado Editora, 2011

; FIGUEIREDO, Mariana Filchtiner. Reserva do possível, mínimo existencial e direito à saúde: algumas aproximações. Revista de doutrina da $4^{\mathbf{a}}$ região, Porto Alegre $(\mathrm{RS})$, 24.ed..2008.Disponível.em:<http://www.revistadoutrina.trf4.jus.br/index.htm?http://www.revi stadoutrina.trf4.jus.br/artigos/edicao024/ingo_mariana.html >. Acesso em 10 mar. 2019.

; ZANCANER Zockun, Carolina. Notas sobre o mínimo existencial e sua interpretação pelo STF no âmbito do controle judicial das políticas públicas com base nos direitos sociais. Revista de Investigações Constitucionais. Curitiba, v.3(2), p.115-141, maio/agosto 2016.

SCHAFER, Jairo. Classificação dos direitos fundamentais. Porto Alegre: Livraria do Advogado, 2013. 
SILVA, José Afonso da. Curso de direito constitucional positivo. 30 ed. São Paulo: Malheiros, 2008. 